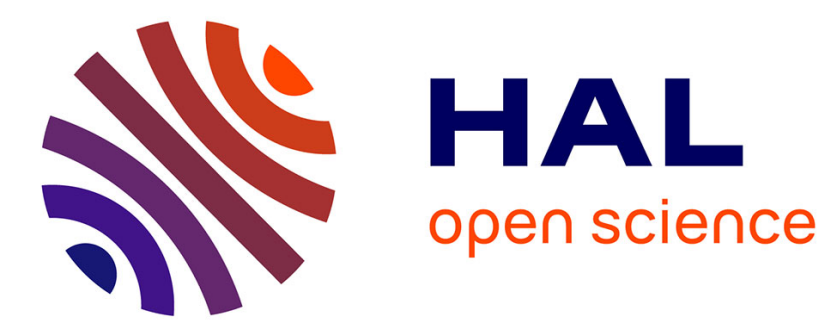

\title{
Medicago truncatula Zinc-Iron Permease6 provides zinc to rhizobia-infected nodule cells
}

\author{
Isidro Abreu, Ángela Saéz, Rosario Castro-Rodríguez, Viviana Escudero, \\ Benjamín Rodríguez-Haas, Marta Senovilla, Camille Larue, Daniel \\ Grolimund, Manuel Tejada-Jiménez, Juan Imperial, et al.
}

\section{To cite this version:}

Isidro Abreu, Ángela Saéz, Rosario Castro-Rodríguez, Viviana Escudero, Benjamín Rodríguez-Haas, et al.. Medicago truncatula Zinc-Iron Permease6 provides zinc to rhizobia-infected nodule cells. Plant, Cell and Environment, 2017, 40 (11), pp.2706-2719. 10.1111/pce.13035 . hal-02325072

\section{HAL Id: hal-02325072 \\ https://hal.science/hal-02325072}

Submitted on 10 Nov 2020

HAL is a multi-disciplinary open access archive for the deposit and dissemination of scientific research documents, whether they are published or not. The documents may come from teaching and research institutions in France or abroad, or from public or private research centers.
L'archive ouverte pluridisciplinaire HAL, est destinée au dépôt et à la diffusion de documents scientifiques de niveau recherche, publiés ou non, émanant des établissements d'enseignement et de recherche français ou étrangers, des laboratoires publics ou privés. 


\title{
Medicago truncatula Zinc-Iron Permease6 provides zinc to rhizobia-infected nodule cells
}

\author{
Isidro Abreu ${ }^{1 \dagger}$ (D) | Ángela Saéz ${ }^{2 \dagger}$ | Rosario Castro-Rodríguez ${ }^{1}$ | Viviana Escudero ${ }^{1}$ | \\ Benjamín Rodríguez-Haas $^{1 \neq}$ | Marta Senovilla ${ }^{1}$ | Camille Larue ${ }^{2}$ | Daniel Grolimund ${ }^{3}$ | \\ Manuel Tejada-Jiménez ${ }^{1}$ | Juan Imperial ${ }^{1,4}$ | Manuel González-Guerrero ${ }^{1 \S}$
}

${ }^{1}$ Centro de Biotecnología y Genómica de Plantas (UPM-INIA), Campus de Montegancedo, Crta, M-40 km 38, 28223

Pozuelo de Alarcón, Madrid, Spain

${ }^{2}$ ECOLAB, Université de Toulouse, CNRS, INPT, UPS, F-31062 Toulouse, France

${ }^{3}$ Paul Scherrer Institute, Swiss Light Source, microXAS Beamline Project, $\mathrm{CH}-5232$ Villigen, Switzerland

${ }^{4}$ Consejo Superior de Investigaciones Científicas, Madrid, Spain

\section{Correspondence}

Manuel González-Guerrero, Centro de Biotecnología y Genómica de Plantas (UPMINIA), Campus Montegancedo UPM, Crta. M40 km 38, 28223 Pozuelo de Alarcón Madrid, Spain.

Email: manuel.gonzalez@upm.es

$\ddagger$ Present Address

Benjamín Rodríguez-Haas, Red de Estudios Moleculares Avanzados, Cluster Biomimic $®$, Instituto de Ecología A.C. Carretera Antigua a Coatepec, 351 El Haya, 91070 Xalapa,

Veracruz, Mexico

\section{§Present Address}

Manuel Tejada-Jiménez, Department of Biochemistry and Molecular Biology, Universidad de Córdoba, Campus de Rabanales, Edificio Severo Ochoa, Córdoba, Spain

\section{Funding information}

Ministerio de Economía y Competitividad, Grant/Award Number: AGL-2012-32974 and BES-2013-062674; European Research Council, Grant/Award Number: ERC-2013-StG335284

\begin{abstract}
Zinc is a micronutrient required for symbiotic nitrogen fixation. It has been proposed that in model legume Medicago truncatula, zinc is delivered by the root vasculature into the nodule and released in the infection/differentiation zone. There, transporters must introduce this element into rhizobia-infected cells to metallate the apoproteins that use zinc as a cofactor. MtZIP6 (Medtr4g083570) is an M. truncatula Zinc-Iron Permease (ZIP) that is expressed only in roots and nodules, with the highest expression levels in the infection/differentiation zone. Immunolocalization studies indicate that it is located in the plasma membrane of nodule rhizobia-infected cells. Down-regulating MtZIP6 expression levels with RNAi does not result in any strong phenotype when plants are fed mineral nitrogen. However, these plants displayed severe growth defects when they depended on nitrogen fixed by their nodules, losing of $80 \%$ of their nitrogenase activity. The reduction of this activity was likely an indirect effect of zinc being retained in the infection/differentiation zone and not reaching the cytosol of rhizobiainfected cells. These data are consistent with a model in which MtZIP6 would be responsible for zinc uptake by rhizobia-infected nodule cells in the infection/differentiation zone.
\end{abstract}

\section{KEYWORDS}

nodule, symbiotic nitrogen fixation, Zinc-Iron Permease

\section{1 | INTRODUCTION}

Plants require a steady supply of zinc (Broadley, White, Hammond, Zelko, \& Lux, 2007; Frausto da Silva \& Williams, 2001). This element is an essential micronutrient used as cofactor by hundreds of enzymes

\footnotetext{
†Ángela Saéz and Isidro Abreu contributed equally to this work.
}

in a typical cell, including representatives from the six major functional enzyme classes (Finkelstein, 2009). In addition, it also plays an important structural function in one of the largest families of transcription factors, the zinc finger proteins (Laity, Lee, \& Wright, 2001). Zinc, especially in alkaline soils, has low bioavailability leading to plant zinc deficiencies, and consequently, reduced yields and reduced nutritional value (Alloway, 2008; Wessells \& Brown, 2012). As a result, a 
substantial research effort has been directed to discern how plants incorporate zinc from soil (Korshunova, Eide, Clark, Guerinot, \& Pakrasi, 1999), how it is uploaded in the vasculature (Hussain et al., 2004), delivered to the phloem (Ishimaru et al., 2005; Yamaguchi et al., 2012), and carried to the embryo (Olsen et al., 2016). In addition, many of the soluble metal carriers and transcription factors regulating plant zinc nutrition have also been studied (Assunção et al., 2010; Olsen \& Palmgren, 2014; Sinclair \& Krämer, 2012).

In contrast, little is known about how zinc is used in symbiotic nitrogen fixation (SNF) and how it is delivered to nitrogen-fixing organs. This is in spite of the importance that this nutrient has for SNF (Ibrikci \& Moraghan, 1993; O'Hara, 2001), one of the main pathways for nitrogen entry in the biosphere and a likely alternative to the overuse of polluting and expensive synthetic fertilizers (Herridge, Peoples, \& Boddey, 2008; Mus et al., 2016). In its most common form, SNF is carried out by legumes that are able to establish an endosymbiotic relationship in their root nodules with a group of bacteria generally known as rhizobia (van Rhijn \& Vanderleyden, 1995). These organs develop after a complex process triggered by bacterial and plant signals (Downie, 2014; Oldroyd, 2013). As a result, rhizospheric rhizobia penetrate into the nodule primordia following infection threads and are released into plant cells in an endocytic-like process (Catalano, Czymmek, Gann, \& Sherrier, 2006). Within these cells, rhizobia will differentiate into bacteroids surrounded by the plasmalemma-derived symbiosome membrane and are then able to fix $\mathrm{N}_{2}$ into $\mathrm{NH}_{4}{ }^{+}$. In indeterminate-type nodules, such as those presented by Medicago, Vicia, or Pisum, the developmental stages of the nodule can be followed along it, as different developmental zones (Vasse, de Billy, Camut, \& Truchet, 1990). This is due to indeterminate nodules having an apical meristem (Zone I) that grows as older parts are infected by rhizobia (early Zone II). In more mature regions of Zone II, rhizobia will differentiate into bacteroids by endoreduplications. In Zone III, the fixation zone (FZ), bacteroids will start fixing nitrogen, a process facilitated by the sudden loss of oxygen tension happening at the interzone between Zones II and III (Soupène, Foussard, Boistard, Truchet, \& Batut, 1995). Finally, in Zone IV, the nodule senesces and nutrients are recycled (Burton, Harlow, \& Theil, 1998).

In this endosymbiotic relationship, there is intense nutrient trafficking between the symbionts (Udvardi \& Poole, 2013). The ammonia that has been produced in bacteroids is transferred to the host plant through the symbiosome membrane in exchange for photosynthates and mineral nutrients (phosphate, sulphur, iron, and zinc) that are provided by the host plant. In the case of iron, it has been shown that it is delivered by the vasculature and released in the apoplast of Zone II in Medicago truncatula nodules (Rodríguez-Haas et al., 2013), where a plasma membrane transporter introduces the metal into rhizobia-infected cells (Tejada-Jiménez et al., 2015). A similar mechanism has been proposed to occur for other transition micronutrients, zinc among them (González-Guerrero, Matthiadis, Sáez, \& Long, 2014; Rodríguez-Haas et al., 2013). If this is true, a zinc transporter must exist in the plasma membrane of cells in this region of the nodule, that when mutated affects zinc uptake by rhizobia-infected cells.

Candidate transporters to carry out apoplastic zinc uptake would belong to the Yellow Stripe-Like (YSL) or to the Zinc-Iron Permease
(ZIP) families. Phenotypical and biochemical studies indicate that proteins from these groups introduce divalent transition metals $\left(\mathrm{Zn}^{2+}\right.$ among them) into the cytosol of the cell (Curie et al., 2008; Guerinot, 2000). YSLs do this as metal-nicotianamine complexes (DiDonato, Roberts, Sanderson, Eisley, \& Walker, 2004), while no type of complex seems to be necessary for transport by ZIP proteins (Lin, Chai, Love, \& $\mathrm{Fu}, 2010)$. Transcriptomic data show that the ZIP transporter MtZIP6 (Medtr4g083570) is highly expressed in rhizobia-infected cells (Limpens et al., 2013). In addition, another ZIP protein has already been associated with SNF, as being responsible for maintaining zinc homeostasis in the symbiosome in Glycine max (Clarke, Loughlin, Day, \& Smith, 2014; Moreau et al., 2002).

In this study, MtZIP6 was further characterized. The data support that it is responsible for zinc uptake by rhizobia-infected cells in M. truncatula nodules. MtZIP6 expression peaks in the apical parts of the nodule, where its encoded protein is inserted in the plasma membrane. Although it was reported to be a $\mathrm{Zn}^{2+}$ and $\mathrm{Fe}^{2+}$ uptake transporter in yeast (López-Millán, Ellis, \& Grusak, 2004), in planta its role seems to be confined to zinc homeostasis in the context of SNF, because no phenotype was observed under nonsymbiotic conditions, and only zinc homeostasis was affected in nodulated mtzip6 RNAi plants.

\section{I MATERIALS AND METHODS}

\section{1 | Biological materials and growth conditions}

M. truncatula R108 seed scarification was performed by incubation for 7 min with concentrated $\mathrm{H}_{2} \mathrm{SO}_{4}$. Once washed, seeds were surface sterilized with $50 \%$ bleach for $90 \mathrm{~s}$ and left overnight in sterile water. After $48 \mathrm{hr}$ at $4{ }^{\circ} \mathrm{C}$, seeds were germinated in water-agar plates at $22{ }^{\circ} \mathrm{C}$ for $48 \mathrm{hr}$. Then, seedlings were transplanted to sterilized perlite pots and inoculated with Sinorhizobium meliloti 2011 or S. meliloti 2011 transformed with the green fluorescent protein (GFP) expressing pHC60 vector (Cheng \& Walker, 1998), as indicated. Plants were cultivated in a greenhouse in $16 \mathrm{hr}$ of light and $22{ }^{\circ} \mathrm{C}$ conditions and watered every 2 days with Jenner's solution or water, alternatively (Brito, Palacios, Hidalgo, Imperial, \& Ruíz-Argüeso, 1994). Nodules were collected $28 \mathrm{dpi}$. Nonnodulated plants were grown in similar conditions of light and temperature, but instead of being inoculated with S. meliloti, they were watered every 2 weeks with solutions supplemented with $2 \mathrm{mM} \mathrm{NH}_{4} \mathrm{NO}_{3}$. For hairy-root transformations, M. truncatula seedlings were transformed with Agrobacterium rhizogenes ARqua1 carrying the appropriate binary vector as described (Boisson-Dernier et al., 2001).

\section{2 | RNA extraction and quantitative Polymerase Chain Reaction (qPCR)}

RNA was isolated using Tri-Reagent (Life Technologies, Carlsbad, CA), DNase treated and cleaned with RNeasy Minikit (Qiagen, Valencia, CA). Putative DNA contamination on RNA isolation was tested by Polymerase Chain Reaction (PCR) employing M. truncatula ubiquitin carboxyl-terminal hydrolase (Medtr4g077320.1) primers (Table S1). Denaturing agarose gel was used to verify RNA quality; $1 \mu \mathrm{g}$ of 
DNA-free RNA was employed to generate cDNA by using SuperScript III reverse transcriptase (Invitrogen). Gene expression was determined by quantitative real time Reverse-Transcription Polymerase Chain Reaction (RT-PCR) (9700, Applied Biosystems, Carlsbad, CA) using primers listed in Table S1. The M. truncatula ubiquitin carboxyl-terminal hydrolase gene was used to normalize the results (Kakar et al., 2008). Real-time cycler conditions have been previously described (GonzálezGuerrero, Raimunda, Cheng, \& Argüello, 2010). mRNA was extracted from three pooled plants from an independent experiments each, with the threshold cycle $(\mathrm{Ct})$ determined in triplicate. The relative levels of transcription were calculated using the $2^{-\Delta C t}$ method. As control, a non-RT sample was used to detect any possible DNA contamination.

\section{3 | GUS staining}

A transcriptional fusion was constructed by amplifying $2 \mathrm{~kb}$ upstream of MtZIP6 start codon using primers indicated in Table S1, cloned in pDONR207 (Invitrogen) and transferred to pGWB3 (Nakagawa et al., 2007) using Gateway technology (Invitrogen). This led to the fusion of the promoter region of MtZIP6 with the gus gene in pGWB3. pGWB3::MtZIP6 was transformed in A. rhizogenes ARqua1 and used to obtain $M$. truncatula composite root plants as indicated (BoissonDernier et al., 2001). GUS activity was determined in 28 dpi plants as described (Vernoud, Journet, \& Barker, 1999). The process was carried out from biological material originating from three independent assays carried out at different times of the year to select a representative image.

\section{4 | MtZIP6 knockdown plants}

A DNA fragment of the first 469 bp of the MtZIP6 coding region was amplified by PCR using the primers indicated in Table S1 and cloned into the pFRN destination vector (derived from pFGC5941; NCBI accession number AY310901) using Gateway technology (Invitrogen). The DNA fragment is inserted twice in this vector in opposite orientations and flanking an intron so that upon transcription, a hairpin double stranded RNA structure is formed. The resulting construct pFRN:: MtZIP6KD was transformed into A. rhizogenes ARqua1 (Quandt, Pühler, \& Broer, 1993) and used for M. truncatula root transformation. The transgenic roots were obtained after kanamycin selection as described Boisson-Dernier et al. (2001). Specificity and efficiency of silencing was checked using real time RT-PCR using the primers indicated in Table S1. Plants transformed with pFRN containing 450 bp of the gus gene was used as a control for all the assays involving silenced plants.

\section{5 | Confocal microscopy detection of MtZIP6-HA}

By using Gateway technology (Invitrogen), a DNA fragment of the fulllength MtZIP6 genomic region and the $2 \mathrm{~kb}$ upstream of its start codon was cloned in the plasmid pGWB13 (Nakagawa et al., 2007). This plasmid fuses three C-terminal hemagglutinin (HA) tags in-frame. Hairy-root transformation was performed as previously described. Transformed plants were inoculated with S. meliloti 2011 containing the pHC60 plasmid that constitutively expresses GFP. Roots and nodules collected from 28 dpi plants were fixed by overnight incubation in
$4 \%$ paraformaldehyde, $2.5 \%$ sucrose in PBS at $4{ }^{\circ} \mathrm{C}$. After washing in PBS, nodules were cut in 100- $\mu \mathrm{m}$ sections with a Vibratome 1000 plus (Vibratome, St. Louis, MO). Sections were dehydrated in a methanol series $(30 \%, 50 \%, 70 \%$, and $100 \%$ in PBS) for 5 min and then rehydrated. Cell walls were treated with $4 \%$ cellulose in PBS for $1 \mathrm{hr}$ at room temperature and with $0.1 \%$ Tween 20 in Phosphate Buffer Saline (PBS) for an additional $15 \mathrm{~min}$. Sections were blocked with 5\% bovine serum albumin in PBS before their incubation with an anti-HA mouse monoclonal antibody (Sigma, St. Louis, MO) for $2 \mathrm{hr}$ at room temperature. After washing, an Alexa 594-conjugated anti-mouse rabbit monoclonal antibody (Sigma) was added to the sections for $1 \mathrm{hr}$ at room temperature. DNA was stained with DAPI after washing. Images were acquired with a confocal laser-scanning microscope (Leica SP8, Wetzlar, Germany). The specific settings for each probe are listed in Table S2. The process was carried out from biological material originating from three independent assays carried out at different times of the year to select a representative image.

\subsection{Acetylene reduction assay}

Nitrogenase activity was measured by the acetylene reduction assay (Hardy, Holsten, Jackson, \& Burns, 1968). Nitrogen fixation was assayed in RNAi and control plants $28 \mathrm{dpi}$ in $30 \mathrm{ml}$ tubes fitted with rubber stoppers. Each tube contained roots from five independently transformed plants. Three milliliters of air inside were replaced with $3 \mathrm{ml}$ of acetylene. Tubes were incubated at room temperature for $30 \mathrm{~min}$. Gas samples $(0.5 \mathrm{ml})$ were analysed in a Shimadzu GC-8A gas chromatograph fitted with a Porapak $\mathrm{N}$ column. The amount of ethylene produced was determined by measuring the height of the ethylene peak relative to background. Each point consists of three tubes each with five pooled plants measured in triplicate. After measurements, nodules were recovered from roots to measure their biomass.

\section{7 | Metal content determination}

Total reflection X-ray fluorescence (TXRF) analysis was used to determine iron and zinc content in $28 \mathrm{dpi}$ mutant nodules isolated and pooled from 3 sets of 10 plants each. Analyses were carried out at TXRF laboratory from Interdepartmental Research Service (SIdl), Universidad Autónoma de Madrid (Spain). This analysis was performed with a S2 PicoFox TXRF spectrometer from Bruker Nano $\mathrm{GmbH}$, equipped with a molybdenum X-ray source working at $50 \mathrm{kV}$ and $600 \mu \mathrm{A}$, a multilayer monochromator with $80 \%$ of reflectivity at $17.5 \mathrm{keV}$ (Mo Ka), a XFlash SDD detector with an effective area of $30 \mathrm{~mm}^{2}$, and an energy resolution better than $150 \mathrm{eV}$ for $\mathrm{Mn} \mathrm{Ka}$. Nodule samples were mineralized with $\mathrm{HNO}_{3}$ (Suprapur) by high temperature and pressure in a Milestone UltraWave microwave digestion system. Selenium was used as an internal standard.

Inductively coupled plasma mass spectrometry ICP-MS) was carried out at the Unit of Metal Analysis from the Scientific and Technology Centre, Universidad de Barcelona (Spain). These samples were digested with $\mathrm{HNO}_{3}, \mathrm{H}_{2} \mathrm{O}_{2}$, and $\mathrm{HF}$ in a teflon reactor at $90^{\circ} \mathrm{C}$. The sample was diluted with deionized water. Final volume was calculated by weight and weight/volume ratio. The samples were digested with 
three blanks in parallel. Metal determination was carried out in Agilent 7500ce under standard conditions. Calibration was carried out with five solution prepared from certified NIST solutions.

\section{8 | Zinc imaging}

Zinc distribution was visualized with the fluorophore Zinpyr-1 as previously reported (Sinclair, Sherson, Jarvis, Camakaris, \& Cobbett, 2007) with some modifications. Briefly, nodules were hand-sectioned, incubated during $15 \mathrm{~min}$ in the dark at room temperature with $200 \mu \mathrm{M}$ Zinpyr-1 freshly prepared in PBS, and washed three times with PBS. Nodule sections were immediately observed under a Leica SP8 confocal microscope using excitation at $488 \mathrm{~nm}$ and emission filter at 500-550 nm.

Zinpyr-1 fluorescence quantification was analysed using FIJ software (v.1.47p). For each section, different planes in $z$ axis were stacked using maximum intensity projection, and fluorescence intensity was calculated using "Plot profile" tool from two regions of interest, apical zone and FZ, being relativized by the area of each region. Sections from 5 to 12 nodules, each from an independently transformed plant, were analysed to discard variations in the grade of silencing. The settings used for this assay are listed in Table S2. Representative images for the plants analysed are showed (Figure S8).

\section{9 | Sequence analysis}

To identify M. truncatula ZIP family members, BLASTN and BLASTX searches were carried out in the M. truncatula Genome Project site (http://www.jcvi.org/medicago/index.php). Sequences from model ZIP genes were obtained from the Transporter Classification Database (http://www.tcdb.org/; Saier, Reddy, Tamang, \& Västermark, 2014), NCBI (http://www.ncbi.nlm.nih.gov/), and Phytozome (https:// phytozome.jgi.doe.gov/pz/portal.html): Arabidopsis thaliana AtZIP1 (At3g12750), AtZIP2 (At5g59520), AtZIP3 (At2g32270), AtZIP4 (At1g10970), AtZIP5 (At1g05300), AtZIP6 (At2g30080), AtZIP7 (At2g04032), AtZIP8 (At5g45105), AtZIP9 (At4g33020), AtZIP10 (At1g31260), AtZIP11 (At1g55910), AtZIP12 (At5g62160), AtIRT1 (At4g19690), AtIRT2 (At4g19680), AtIRT3 (At1g60960), AtIAR1 (At1g68100), AtZPT29 (At3g20870), AtPutZnT (At3g08650); Oryza sativa OsZIP1 (Os01g74110), OsZIP2 (Os03g29850), OsZIP3 (Os04g52310), OsZIP4 (Os08g10630), OsZIP5 (Os05g39560), OsZIP6 (Os05g07210), OsZIP7 (Os05g10940), OsZIP8 (Os07g12890), OsZIP9 (Os05g39540), OsZIP10 (Os06g37010), OsZIP11 (Os05g25194), OsZIP13 (Os02g10230), OsZIP14 (Os08g36420), OsZIP16 (Os08g01030), OsIRT1 (Os03g46470), OsIRT2 (Os03g46454); Zea mays ZmZIP1 (GRMZM2G001803), ZmZIP3 (GRMZM2G045849), ZmZIP5 (GRMZM2G064382), ZmZIP6 (GRMZM2G034551), ZmZIP7 (GRMZM2G015955), ZmZIP8 (GRMZM2G093276); Phaseolus vulgaris PvZIP1 (Phvul.001G035800), PvZIP4 (Phvul.002G184200), PvZIP5 (Phvul.005G048900), PvZIP6 (Phvul.005G145900), PvZIP7 (Phvul.005G146000), PvZIP8 (Phvul.005G149800), PvZIP9 (Phvul.006G001000), PvZIP11 (Phvul.006G003300), PvZIP12 (Phvul.006G055800), PvZIP13 (Phvul.006G070200), PvZIP14 (Phvul.008G079500), PvZIP15 (Phvul.008G259200), PvZIP16 (Phvul.008G290500), PvZIP17 (Phvul.010G059200), PvZIP18
(Phvul.011G058500), PvZIP19 (Phvul.002G099700), PvIRT1 (Phvul.003G262400), PvIRT2 (Phvul.003G262500), PvIRT3 (Phvul.009G077700), PvZIPT (Phavu.Phvul.L002700); Glycine max GmZIP1 (Glyma.20G063100); Pisum sativum PsRIT1 (AF065444); Lycopersicum esculentum LeIRT1 (AF136579); and Saccharomyces cerevisiae ScZRT1 (NP_011259). The substrate for many of these genes have been previously reported (Table S3)

Protein sequences were processed with MEGA7 (http://www. megasoftware.net): First, protein sequences were aligned using the ClustalW algorithm (http://www.ebi.ac.uk/Tools/msa/clustalw2/), and the alignment was visually examined to exclude alignment artefacts. Then, phylogenetic reconstruction was performed using the neighbor-joining method, the Jones-Taylor-Thornton substitution model and assuming uniform rates. Deletion sites were excluded from the alignment following the partial deletion method (95\% site coverage cut-off). Unrooted tree visualization was carried out using FigTree (http://tree.bio.ed.ac.uk/software/figtree/). Previously described M. trunctula ZIP1-7 annotation was maintained: MtZIP1 (Medtr2g064310), MtZIP2 (Medtr2g097580), MtZIP3 (Medtr3g081580), MtZIP4 (Medtr3g082050), MtZIP5 (Medtr1g016120), MtZIP6 (Medtr4g083570), and MtZIP7 (Medtr3g058630); whereas new MtZIP members were annotated sequentially: MtZIP8 (Medtr2g098150), MtZIP9 (Medtr3g081640), MtZIP10 (Medtr3g081690), MtZIP11 (Medtr3g104400), MtZIP12 (Medtr4g065640), MtZIP13 (Medtr5g071990), MtZIP14 (Medtr6g007687), MtZIP15 (Medtr7g074060), and MtZIP16 (Medtr8g105030).

\subsection{0 | Statistical tests}

Data were analysed by Student's unpaired $t$ test to calculate statistical significance of observed differences. Test results with $p$ values less than .05 were considered as statistically significant.

\section{3 | RESULTS}

\section{1 | MtZIP6 is highly expressed in nodules}

Real-time quantitative PCRs were used to determine MtZIP6 expression in roots and shoots from noninoculated, nitrogen-fertilized M. truncatula R108 plants, and in roots, nodules, and shoots from plants inoculated with S. meliloti (Figure 1a). No transcripts were detected in shoots either in inoculated or noninoculated plants. In roots, nodulation appeared to cause no significant change in transcript levels. However, the expression maximum was reached in nodules, with over four times the levels detected in nitrogen-fertilized, noninoculated roots. Sequence comparison of the 16 ZIP proteins encoded in M. truncatula genome with those from other plants show that there is little correlation between sequence similarity and substrate preference for a determined divalent transition metal within the ZIP family (Figure 1b). MtZIP6 shares little similarity to GmZIP1, a ZIP family member reported to be nodule-specific in G. max (Moreau et al., 2002). This suggests that both transporters could play different roles in the nodules. This is further indicated by their different substrate preference in yeast, because GmZIP1 transports $\mathrm{Zn}^{2+}$ towards the cytosol, and MtZIP6 also transports $\mathrm{Fe}^{2+}$ in the same direction 
(a)

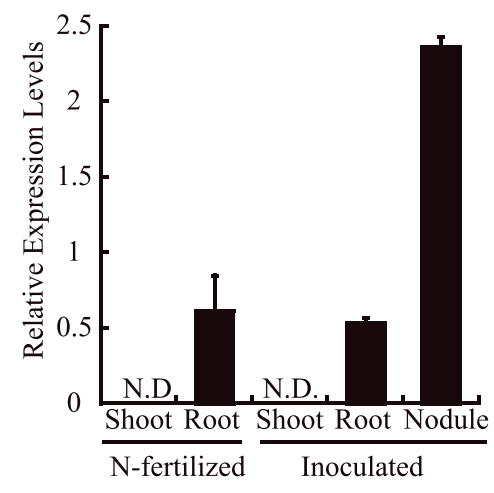

(b)

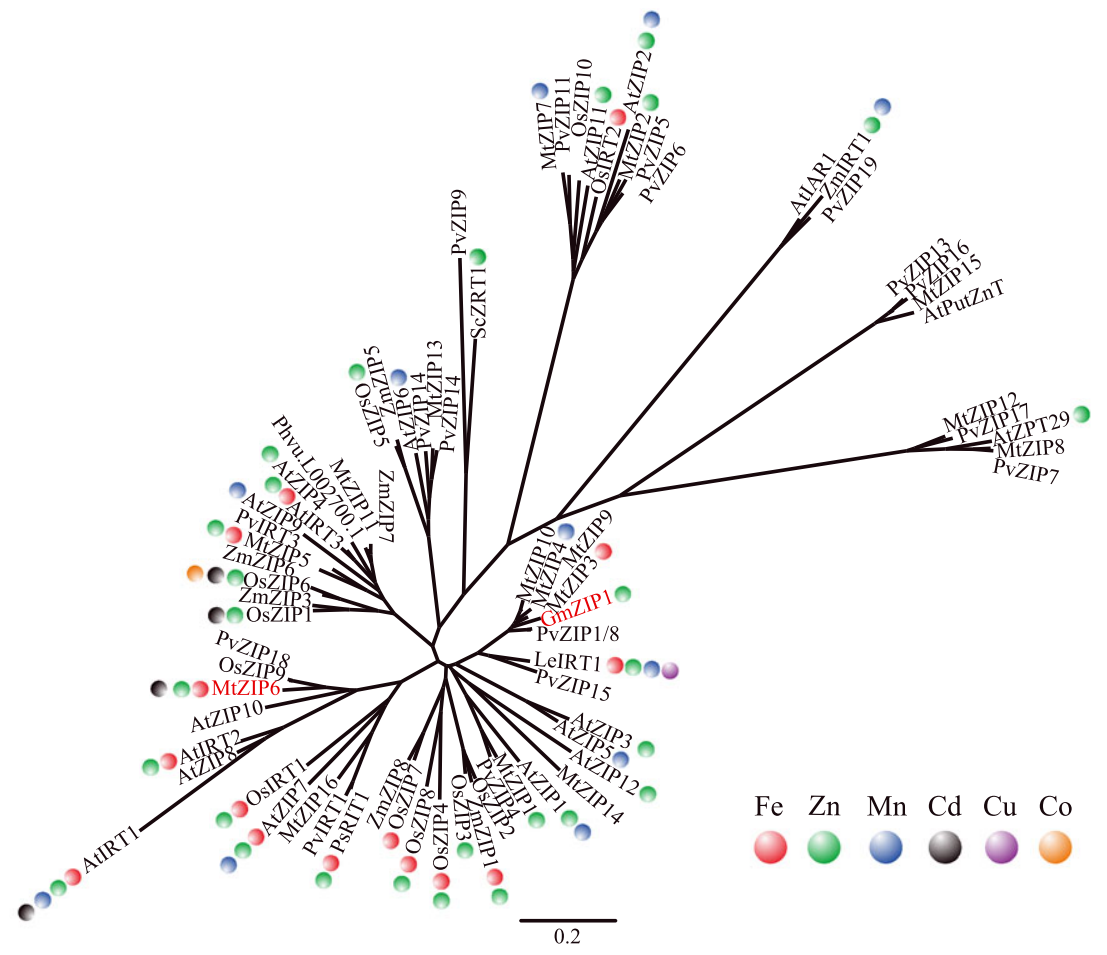

FIGURE 1 MtZIP6 gene expression and relationship to other plant Zinc-Iron Permease (ZIP) family members. (a) MtZIP6 expression in roots, shoots, and nodules relative to internal standard gene ubiquitin carboxyl-terminal hydrolase. Data are the mean \pm SD of three independent experiments. N.D. indicates that transcripts were undetectable. (b) unrooted tree of Medicago truncatula ZIP transporters and representative plant ZIP homologues (see Section 2). Coloured circles indicate proposed metal substrate according to literature

(López-Millán et al., 2004). Although MtZIP6 shares little relationship with the other 15 ZIP family members in M. truncatula, MtZIP16 is the closest (72\% similarity; Figure $1 \mathrm{~b})$.

\subsection{MtZIP6 is localized in the plasma membrane of cells in the infection/differentiation zone of the nodule}

Metal release from the vasculature into the nodule appears to be primarily carried out in the differentiation zone of the nodule (Rodríguez-Haas et al., 2013). There, transporters must translocate the metals into the rhizobia-infected cells. Should MtZIP6 be carrying out this function, it will primarily be expressed in the proximities of the differentiation zone and the following cell layers. To test this, $\beta$-glucuronidase (GUS) activity was determined in M. truncatula plants expressing the gus gene under the transcriptional control of a DNA fragment containing $2 \mathrm{~kb}$ upstream from MtZIP6 start codon. The reporter assays indicate that MtZIP6 is primarily expressed in the apical regions of the nodule and in the root vasculature (Figure 2a). Sections of these organs showed that in nodules, the expression was located in the differentiation zone (Zone II) and in the younger parts of the FZ (Zone III; Figure 2b). This expression pattern along the different nodule zones is in agreement with the transcriptomic data from the Symbimics database (Roux et al., 2014). These data were obtained from RNA extracted from laser-capture microdissected M. truncatula nodule cells from the Zone I, early and late Zone II, Interzones II-III, and Zone III. Figure 2c shows that the majority of the transcripts are detected in the older part of Zone II, the interzone, and Zone III, the areas with the maximum GUS activity (Figure 2c). In the roots, MtZIP6 is expressed in the vasculature around the xylem (Figure $2 \mathrm{~d}$ ).

Further validation of these results was obtained in plants transformed with MtZIP6, whole gene structure (introns + exons) under the control of the same promoter region used in the GUS expression assays, fused to three HA epitopes in C-terminus (MtZIP6-HA). Addition of this tag had no major effect on the functionality of the protein, because both HA-tagged and un-tagged MtZIP6 could complement 
(a)

FIGURE 2 Tissular localization of MtZIP6 expression. (a) Histochemical staining of GUS activity in the root and nodules of Medicago truncatula plants transformed with plasmid pGWB3 containing the MtZIP6-promoter:gus fusion. Scale bar represents $1 \mathrm{~mm}$. (b) Longitudinal section of GUS stained nodule from M. truncatula plants transformed with plasmid pGWB3 containing the MtZIP6promoter:gus fusion. Scale bar represents $200 \mu \mathrm{m}$. (c) Expression of MtZIP6 in the different nodule zones: FI indicates Zone I; Flld, early Zone II (closest to Zone I); Fllp, late Zone II; IZ is the interzone between Zones II and III; and ZIII, Zone III. Data were obtained from the Symbimics database (https://iant. toulouse.inra.fr/symbimics). (d) Cross section of a GUS-stained root from $M$. truncatula plants transformed with plasmid pGWB3 containing the MtZIP6-promoter:gus fusion. Scale bar represents $100 \mu \mathrm{m}$. Epi. indicates epidermis; end., endodermis; and vasc., the vascular cylinder

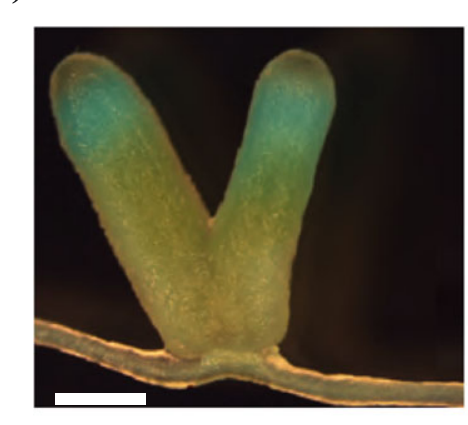

(c)

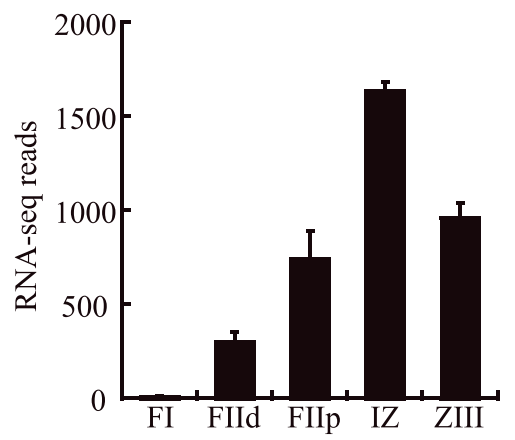

(b)

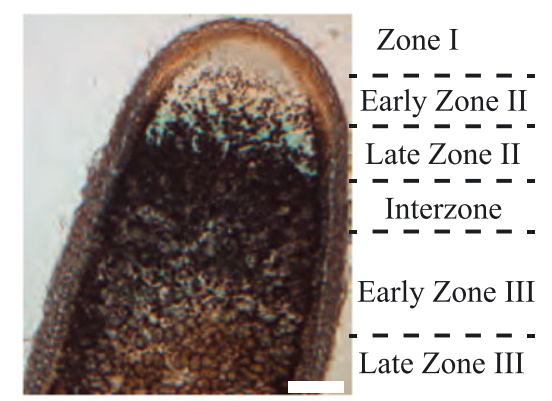

(d)

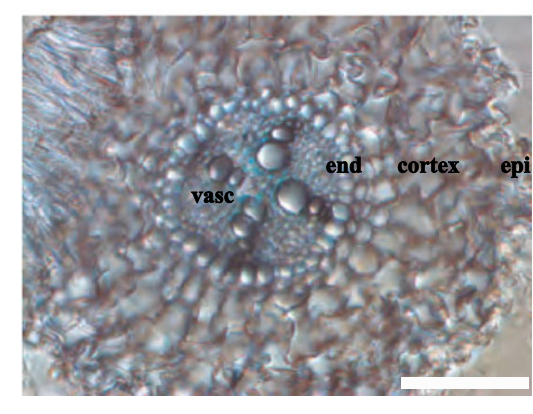

the zinc uptake phenotype of yeast mutant zrt1/zrt2 (Figure S1). MtZIP6-HA was detected using an Alexa594-conjugated antibody, and its position within the nodule was mapped with the help of DAPI, to stain DNA, and a constitutive GFP-expressing S. meliloti. As expected, the immunolocalization studies supported the histochemistry results, showing that MtZIP6-HA was primarily located in the differentiation zone of the nodules (distal ZII-apical ZIII). Alexa594 signal was not detected in older parts of the FZ, nor in the meristematic or in the infection areas (Figure 3a). At the cellular level, MtZIP6 was detected in the periphery of the rhizobia-infected cells, indicative of the plasma membrane or a region close to it (Figure 3b). No MtZIP6 was detected in rhizobia-free cells in Zone II. To confirm the putative plasma membrane localization, MtZIP6 coding sequence was fused to a GFP tag under the control of a $35 \mathrm{~S}$ promoter and coagroinfiltrated into Nicotiana benthamiana leaves with a cyan fluorescent protein-labelled AtPIP2A plasma membrane marker (Nelson, Cai, \& Nebenführ, 2007). Those cells that expressed both constructions showed an overlap of the GFP and cyan fluorescent protein signals, consistent with a colocalization in the plasma membrane (Figure S2). In roots, as already indicated by the GUS expression assays, MtZIP6-HA was localized in the stele, in close proximity to the xylem (Figure $3 c$ ).

\subsection{MtZIP6 silencing has a negative effect on SNF}

To study the role of MtZIP6 in plant metal nutrition and in SNF, RNAi plants were produced by $A$. rhizogenes transformation. Given that MtZIP6 was not expressed in shoots, hairy-root transformed plants would be sufficient to study the effect that down-regulating MtZIP6 has on the plant. However, as no germ-line transformants were produced, and given that gene silencing can vary from one line to another, pooled plants were used in these analyses to average the effects of each independent T-DNA insertion event. Using the first $469 \mathrm{bp}$ of MtZIP6 cDNA to silence, the gene resulted in an average $80 \%$ reduction of expression (Figure 4a). No reduction on transcript levels was observed in any of the three ZIP family members with the highest degree of identity to MtZIP6 (MtZIP5, MtZIP11, and MtZIP16; Figure S3) Under nonsymbiotic conditions, when plants were not inoculated and the nutrient solution was supplemented with $\mathrm{NH}_{4} \mathrm{NO}_{3}$, no alteration in growth was observed between mtzip6 RNAi plants and controls, which express $450 \mathrm{bp}$ of the gus gene in the same vector as the RNAi plants (Figure 4b). Similarly, no significant differences were observed when comparing shoot and root dry biomass between control and RNAi plants (Figure 4c).

In contrast, when the plants were inoculated with S. meliloti and no fixed nitrogen was provided in the nutrient solution used to water them, plant growth was severely affected in mtzip6 RNAi plants (Figure 5a). These plants showed reduced biomass production, with an average reduction of $70 \%$ in shoots and $68 \%$ in roots (Figure 5b). Nodule development was affected, with approximately half of the nodules smaller than normal and white, suggesting they are non-functional (Figure 5c,d). These observations are the likely result of an impairment in nodule function, with a subsequent reduction in nitrogenase activity. To measure this activity, the acetylene reduction assay (Hardy et al., 1968) was used. On average, RNAi plants showed an $80 \%$ reduction in nitrogenase activity per plant when compared to controls (Figure 5e), which was not due either to a reduction in the nitrogenase protein (Figure S4) or to a reduction on the number of rhizobia per nodule (Figure S5). These results obtained from pooling plants were consistent with the average of analysing individual plants resulting each from one independent transformation event (Figure S6). 
(a)
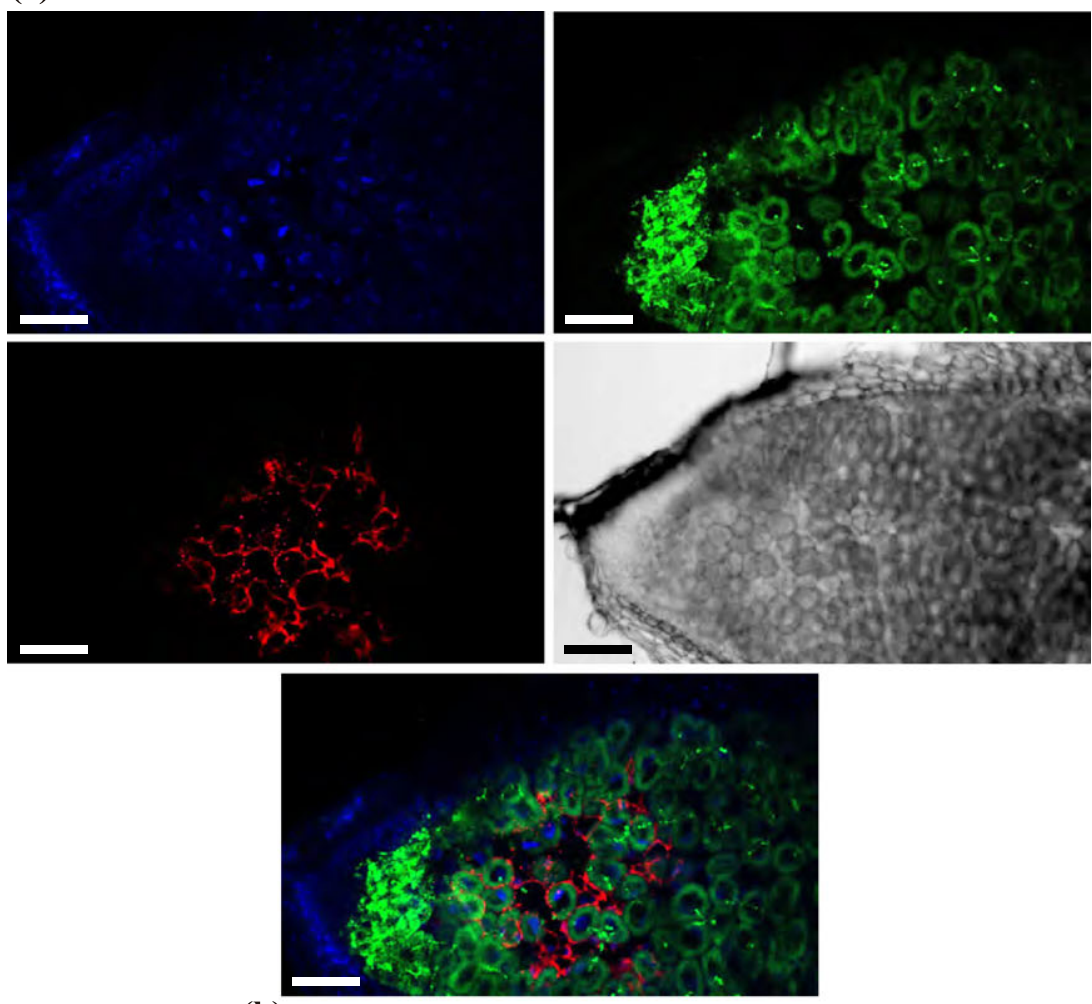

(b)

(c)
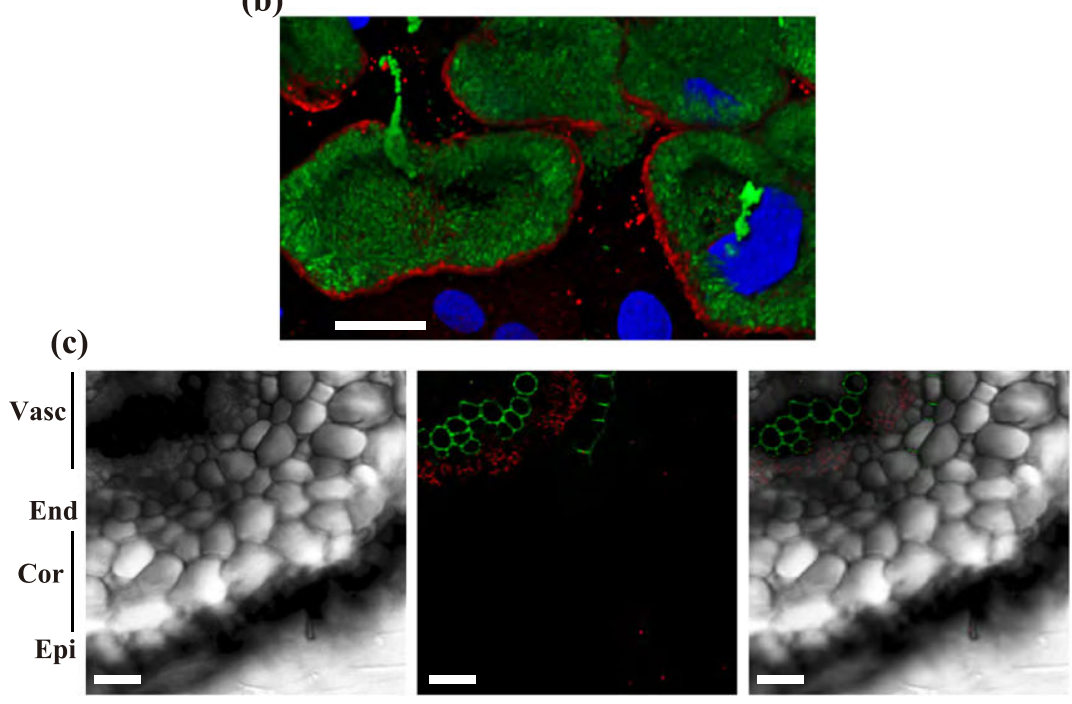

FIGURE 3 Subcellular localization of MtZIP6HA. (a) Cross section of a 28 dpi Medicago truncatula nodule inoculated with Sinorhizobium meliloti constitutively expressing green fluorescent protein (green, upper right panel) and transformed with a vector expressing the fusion MtZIP6-HA under the regulation of its endogenous promoter. Nodules were stained with DAPI to show DNA (blue, upper left panel). MtZIP6-HA localization was determined using an Alexa 594-conjugated antibody (red, middle left panel). Transmission light (grey, middle right panel) showed nodule structure. Lower panel shows the overlay of DNA, S. meliloti, and MtZIP6-HA. Scale bar represents $100 \mu \mathrm{m}$. (b) Three-dimensional reconstruction of MtZIP6$H A$ expressing cells. Green fluorescent protein-expressing $S$. meliloti are shown in green, red indicates the position of MtZIP6$\mathrm{HA}$, and blue is DAPI-stained DNA. Scale bar represents $25 \mu \mathrm{m}$. (c) Cross section of a M. truncatula root transformed with a vector expressing the fusion MtZIP6-HA under the regulation of its endogenous promoter. Left panel shows the transillumination figure. Middle panel shows MtZIP6-HA localization using an Alexa 594-conjugated antibody (red) and xylem and endodermis layers using autofluorescence (both green). Right panel shows the overlaid images. Scale bar represents $50 \mu \mathrm{m}$. Epi., stands for epidermis; Cor., cortex; End., endodermis; and Vasc., vascular cylinder

\section{4 | MtZIP6 provides zinc to rhizobia-infected nodule cells}

To determine the substrate of MtZIP6, metal content in shoots, roots, and nodules in control and mtzip6 RNAi plants was determined. An increase on zinc content in nodules of mtzip6 RNAi plants was detected (Figure 6a). This result was indicative of a possible role of MtZIP6 in zinc homeostasis, which was also supported by the zincdependent regulation of MtZIP6 expression in roots (Figure 6b). MtZIP6 expression in roots, regardless of whether they are nodulated or not, shows a bimodal expression pattern, with maximum at the lowest and highest zinc concentrations tested. Nodulated roots seem to have a slight, nonsignificant in some cases, expression levels at the suboptimal zinc concentrations $(0-0.26 \mu \mathrm{M})$ when compared to the expression in roots form nonnodulated plants. However, at higher, supraoptimal (3.8 and $39 \mu \mathrm{M}$ ), zinc concentrations, the opposite is observed: MtZIP6 mRNA is more abundant in noninoculated roots. In contrast, MtZIP6 transcription in nodules was not affected by zinc concentrations in the nutrient solution. However, in spite of low zinc-levels upregulating MtZIP6, no significant differences in biomass production or nitrogenase activity were observed between plants grown under low-zinc or standard conditions (Figure S7). Similarly, increasing zinc concentrations in the nutrient solution by 10 or $100-$ fold did not result in a restoration of a wild-type phenotype in mtzip6 RNAi plants (Figure S8), and increasing them by 500 -fold was equally toxic for control and silenced plants (data not shown).

To determine whether silencing MtZIP6 has an effect on zinc distribution, the localization of this element was determined using the zinc-sensitive probe Zinpyr-1 (Sinclair et al., 2007). The images analysed showed that zinc content in control nodules is higher in Zone 
(a)

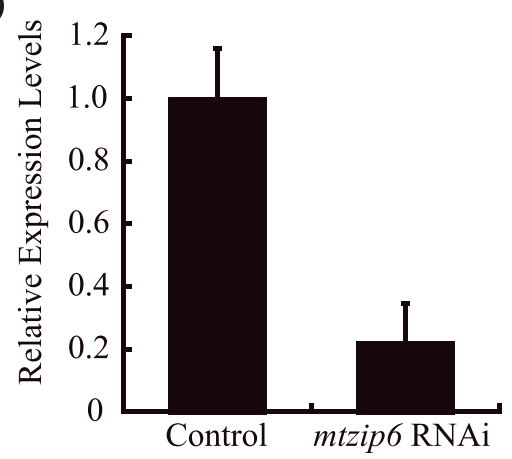

(b)

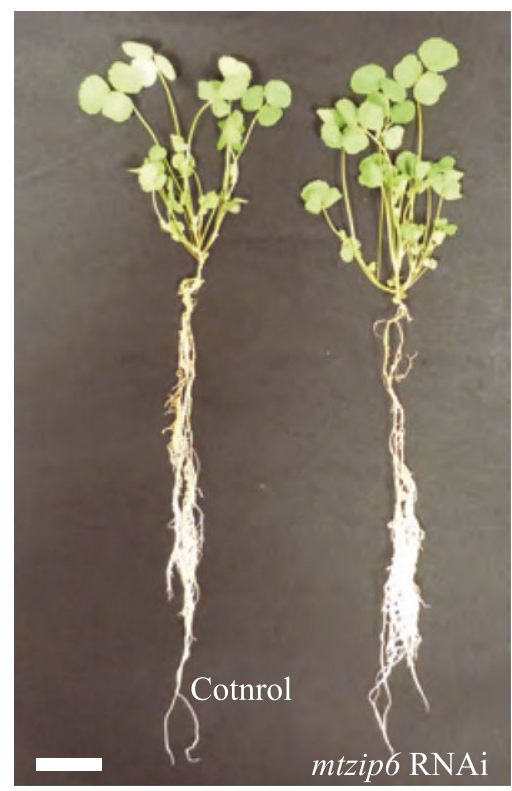

(c)

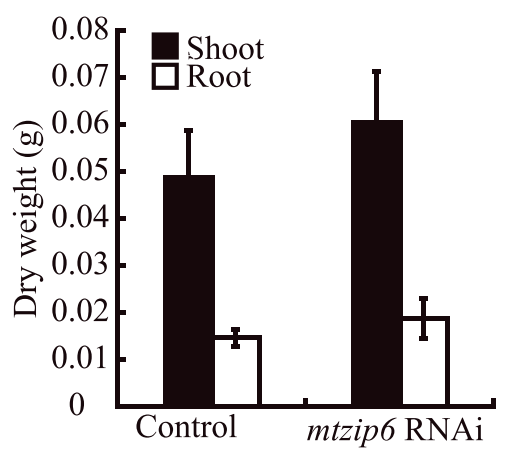

FIGURE 4 Phenotype of mtzip6 RNAi plants under mineral N supply conditions (nonsymbiotic). (a) Expression levels of MtZIP6 in $28 \mathrm{dpi}$ nodules from control and mtzip6 RNAi plants relative to internal standard gene ubiquitin carboxyl-terminal hydrolase and relative to control expression levels. Data are the mean \pm SD of three independent experiments. (b) Growth of representative control and mtzip6 RNAi plants. Scale bar represents $3 \mathrm{~cm}$. (c) Dry weight of shoots and roots. Data are the mean \pm SD ( $n=10$ plants)

III, in the same ring-like distribution that symbiosomes have in the cell (Figure 6c). Silencing MtZIP6 seemed to decrease the Zone III versus Zone II zinc ratio compared to control nodule sections (Figure 6d), specifically in Zone III. At higher magnification, control plants showed very little zinc in the apoplast of late Zone II-Interzone (Figure 6e), and several zinc deposits were detected in the apoplast of the late Zone II-Interzone in mtzip6 RNAi nodules (Figure 6f). This indicates that the increased zinc levels detected in mtzip6 RNAi nodules could be the result of a zinc accumulation in the younger parts of the nodule, prior to the region where MtZIP6 is located. To test this, Zinpyr-1 signals were integrated before and after the interzone of several different nodules and standardized to surface units (selected images are shown in Figure 59). As it is shown in Figure 6g, the apical region of the nodule, corresponding to Zones I and II, had a significantly higher zinc content in RNAi plants than in their controls, and Zone III showed a significant reduction consistent with a reduction in the capacity to translocate zinc into rhizobia-infected cells. To ensure that these observations were not biased by the relative affinities of Zinpyr-1 towards zinc-binding proteins, zinc distribution was also assessed in freeze-dried nodule sections using synchrotron-based X-ray fluorescence. This methodology is based in the excitation of core electrons in atomic orbitals by $\mathrm{X}$-rays. Upon relaxation, fluorescence photons will be emitted that have characteristic energies specific for each element (Punshon, Guerinot, \& Lanzirotti, 2009). The images obtained show that, as observed with the Zinpyr-1 probe (Figure 6c-e), mtzip6 RNAi nodules accumulate more zinc in the apical region than the controls (Figure S10).

To rule out a potential role of MtZIP6 as iron transporter in infected cells, we analysed iron concentration, distribution, and complementation in mtzip6 RNAi plants. In contrast to zinc, there were no significant differences in iron concentration in shoots roots, or nodules between control and mtzip6 RNAi plants (Figure S11a). Increasing iron concentrations in the nutrient solution did not restore the wildtype phenotype in mtzip6 RNAi (Figure S11b). Iron distribution did not change in mtzip6 RNAi plants compared to controls, and no significant differences were observed in the apoplast (Figure S11c and d). In addition, MtZIP6 expression was not altered in nramp1-1, a mutant altered in iron nodule homeostasis (Tejada-Jiménez et al., 2015) and, reciprocally, MtNramp1 expression did not suffer any change in mtzip6 RNAi plants (Figure S12).

\section{4 | DISCUSSION}

Zinc is a limiting nutrient for plants growing in many parts of the world (Alloway, 2008), with severe negative effects on growth, crop yields, and nutritional value (Bashir, Takahashi, Nakanishi, \& Nishizawa, 2013; Wessells \& Brown, 2012). This is even more so in legumes, because they have additional sink organs, the nodules, that demand relatively large amounts of metallic micronutrients (Brear, Day, \& Smith, 2013; González-Guerrero, Escudero, Sáez, \& Tejada-Jiménez, 2016; González-Guerrero et al., 2014; O'Hara, 2001). Consequently, the nutritive properties and yields of legumes, one of the main vegetable protein sources in the world (Boye, Zare, \& Pletch, 2010), rely greatly on our ability to better understand and improve zinc delivery to nitrogen fixation sites. This would also impact the design of future strategies based in ensuring the adequate supply of essential-limiting micronutrients to improve SNF capabilities in legumes or to introduce 
(a)

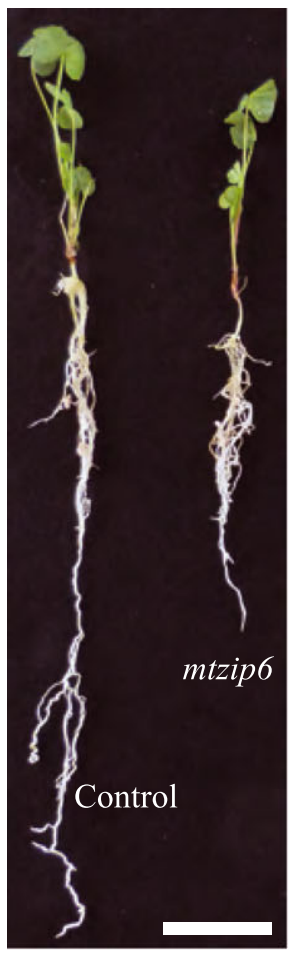

(d)
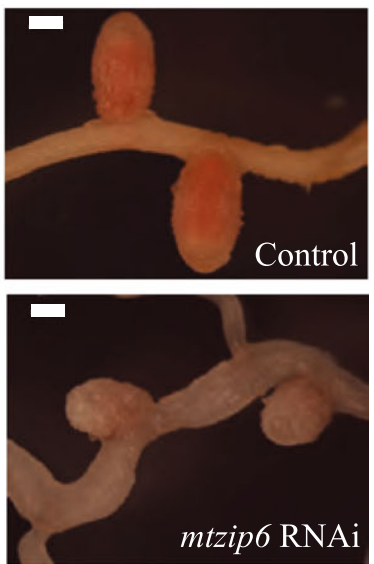

(b)

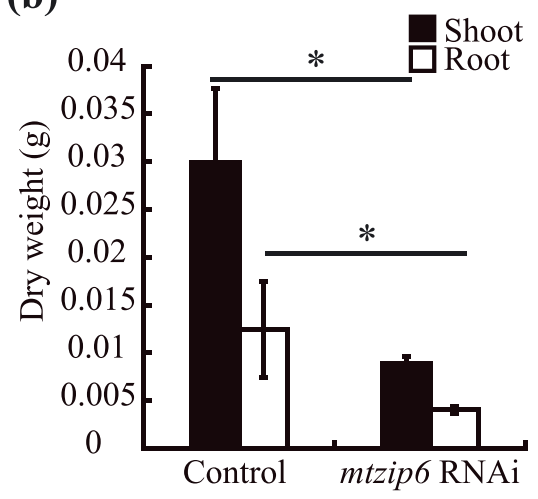

(c)

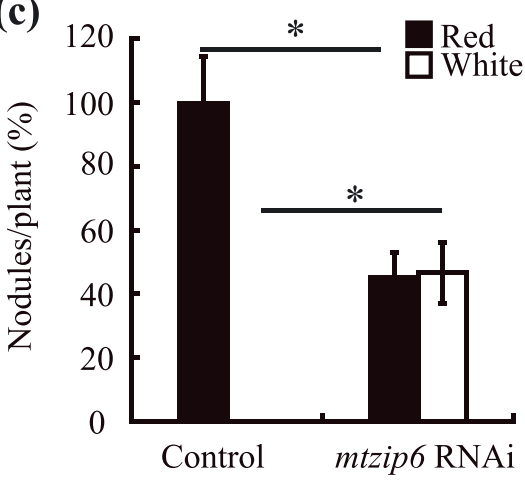

(e)

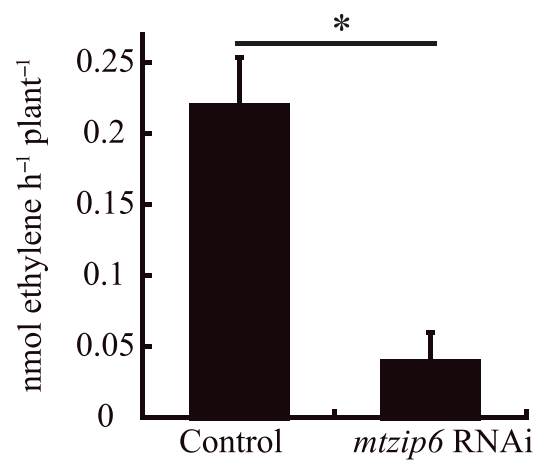

FIGURE 5 Symbiotic phenotype of mtzip6 RNAi plants. (a) Growth of representative control and mtzip6 RNAi plants. Scale bar represents $3 \mathrm{~cm}$. (b) Dry weight of shoots and roots. Data are the mean \pm SD $(n=11-12$ plants). (c) Nodule number per plant. $100 \%=3.48$ nodules/plant. Data are the mean \pm SD ( $n=20$ plants). (d) Close view of a representative control nodule and a white nodule. Scale bar represents $500 \mathrm{~mm}$. (e) Nitrogenase activity in 28 dpi nodules. Data are the mean \pm SD of three sets of five pooled independently transformed plants. Asterisk indicates significant differences $(p \leq .05)$ them in other crops. Using our knowledge on iron delivery to M. truncatula nodules as a model, we hypothesized that (a) zinc is delivered by the vasculature and released in the apoplast of the differentiation zone of the nodule and (b) a ZIP family member that is located in the plasma membrane of cells in this zone of the nodule is responsible for taking up this micronutrient. The results presented here support these hypotheses and point to MtZIP6 as the transporter carrying out this role.

Previous studies had shown that MtZIP6 is a functional ZIP transporter that is able to introduce iron and zinc into yeast cells (López-Millán et al., 2004). This protein was expressed in roots and in the apical region of the nodule. MtZIP6 was located in the plasma membrane of the rhizobia-infected cells in the differentiation zone of the nodule as indicated by transcriptomics, histochemistry, and immunolocalization. Moreover, when MtZIP6 transcript levels were downregulated by RNAi, nitrogen fixation was significantly reduced. All these data support a role of MtZIP6 in SNF, but they do not indicate the nature of the substrate being transported in planta, whether it is introducing zinc into the cell or it is a functional analogue of MtNramp1 involved in iron metabolism (Tejada-Jiménez et al., 2015).

The available evidence indicates that in planta MtZIP6 works primarily as a zinc transporter. The accumulation of zinc in the apical regions of nodules of mtzip6 RNAi plants, where apoplastic zinc deposits were observed, is consistent with a model in which reducing the levels of MtZIP6 would impede zinc transport across the plasma membrane, causing its accumulation in the apoplast and in the nodule region prior to where MtZIP6 is located. It would also explain why no complementation is observed when additional zinc is added to the nutrient solution: It would simply accumulate in the apoplast of the apical region, with very little gaining access to the interior of the cells. Our results also indicate that there must be some systemic signal indicating that zinc is limiting within the cell and that more of this element 
(a)

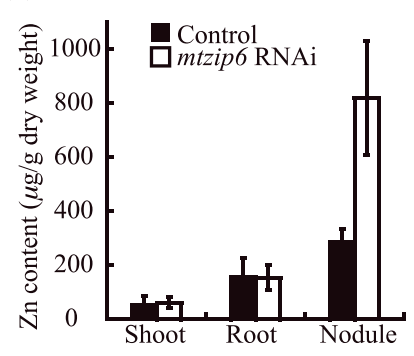

(b)

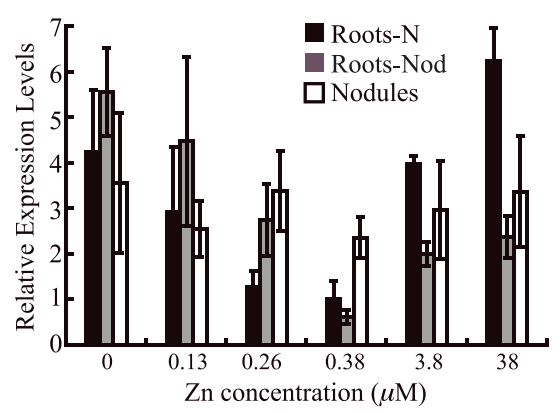

(c)
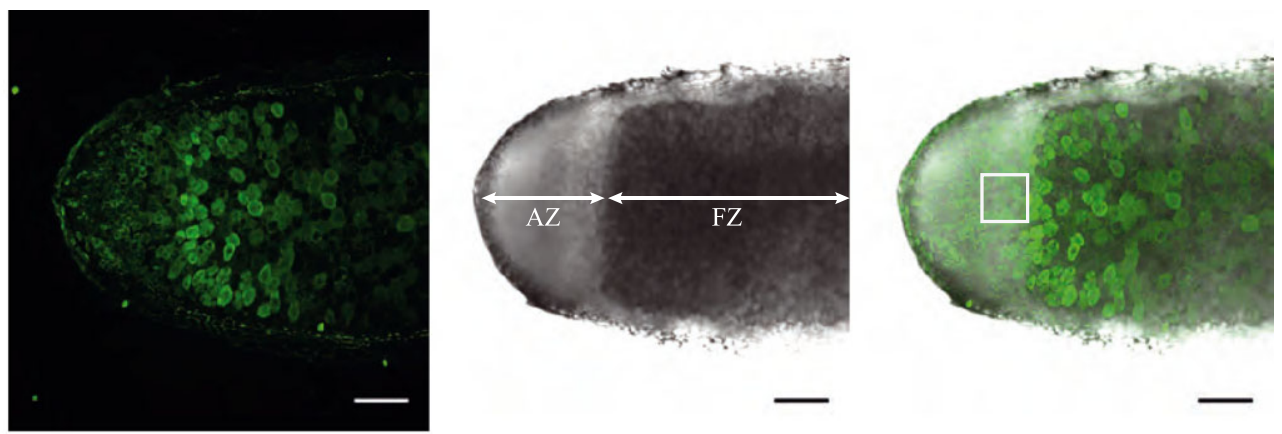

(d)
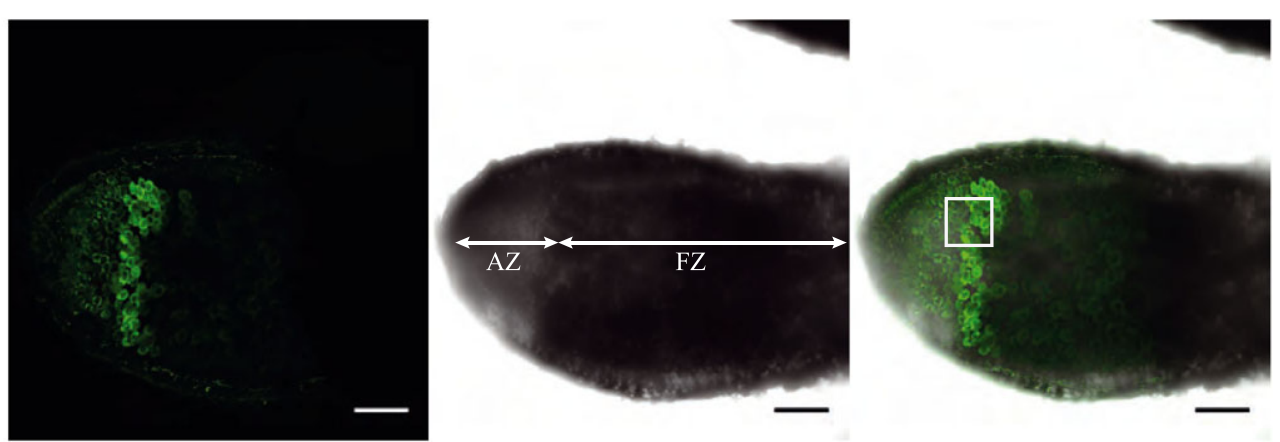

(e)
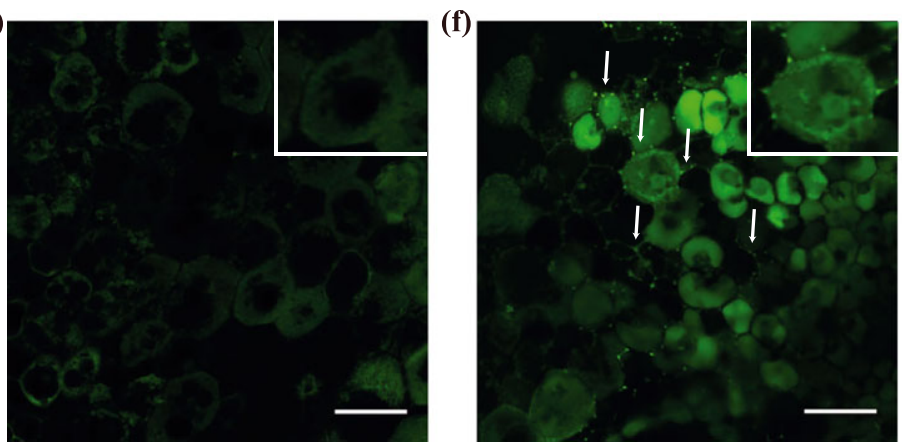

(g)

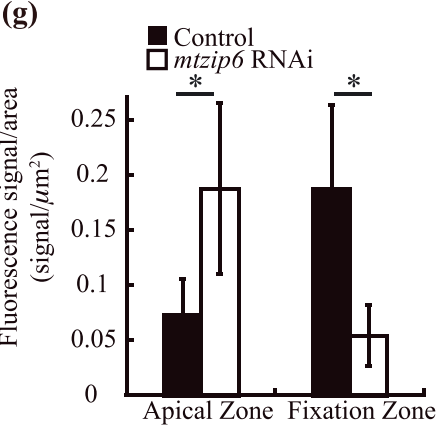

FIGURE 6 Role of MtZIP6 in zinc homeostasis. (a) Zinc content (ppm) in 28 dpi plants. Data are the mean \pm SD of two sets of five pooled transformed plants. (b) Effect of zinc concentration on MtZIP6 expression in roots from nitrogen-fertilized plants and roots and nodules from inoculated ones relative to internal standard gene ubiquitin carboxyl-terminal hydrolase. Data are the mean \pm SD of three independent experiments. (c) Zinc distribution in control nodules determined with Zinpyr-1 (green, left panel), transillumination (middle panel), and overlay (right panel). AZ and FZ indicate apical and fixation zones, respectively. d) Zinc distribution in mtzip6 RNAi nodules determined with Zinpyr-1 (green, left panel), transillumination (middle panel), and overlay (right panel). AZ and FZ indicate apical and fixation zones, respectively. (e) Detail of zinc distribution in the apical zone of control nodules. One cell in this zone is magnified in the inset. (f) Detail of zinc distribution in the apical zone of mtzip6 RNAi nodules. One cell in this zone is magnified in the inset. Arrows indicate apoplastic zinc deposits. (g) Quantification of Zinpyr-1 signal per area in the apical and fixation zones of control and mtzip6 RNAi nodules. Data are the mean \pm SD $(n=5-12$ nodules). Scale bar in c-d represents $200 \mu m$. Scale bar in e-f represents $50 \mu \mathrm{m}$. Asterisk indicates significant differences $(p \leq .05)$

is required, which would explain why nodule zinc concentrations increase in the mtzip6 RNAi nodules rather than remaining equal or even lower. Similar observations have been made when studying two M. truncatula mutants in nodule-specific molybdate and copper transporters (Tejada-Jiménez et al., 2017; Senovilla et al., 2017).
In contrast, MtZIP6 does not appear to play any role in iron homeostasis in nodules. No changes in iron concentration or distribution were observed in mtzip6 RNAi nodules, contrary to what happens in mtnramp1-1 or in ljmate1 plants, both mutants affected in iron homeostasis in nodules (Takanashi et al., 2013; Tejada-Jiménez et al., 
2015). The reported MtZIP6 ability to introduce iron into yeast cells (López-Millán et al., 2004) could simply be the result of overexpressing a transporter with a low iron affinity, that when pressed would transport iron, a phenomenon that is not unusual when assaying heterologous expression in yeast. Moreover, if MtZIP6 were involved in iron transport, we would expect to see an alteration of iron levels in the plant or nodules or a restoration of wild-type growth by watering with added iron, as reported for other transporters involved in iron homeostasis (Takanashi et al., 2013; Tejada-Jiménez et al., 2015). In addition, the expression patterns of MtZIP6 and MtNramp1 do not support the hypothesis that they have a complementary role in the uptake of the same metal. If they were carrying the same micronutrient, some type of coregulation would be observed, in which if one were down-regulated, it might be expected that the other would compensate for the loss of first to prevent unnecessary protein translation. However, the opposite has been observed: Reducing the expression levels of one (by mutation or by RNAi) results in down-regulation of the other.

Consequently, the observed reduction in nitrogenase activity is not the direct result of impaired delivery of a nitrogenase metal cofactor, but rather of the loss of one or several zinc-dependent functions that will affect nodule functioning. Because MtZIP6 is merely introducing zinc in the cytosol, a process that if diminished would affect a wide range of zinc proteins (enzymes, transcription factors, and structural proteins) involved in multiple cellular processes, the observed phenotype could be the result of a complex pleiotropy affecting a host of functions, including nitrogen fixation. Transcriptomic studies from nodule samples already indicate the expression of multiple known zinc proteins (Table S4). However, pinpointing the specific cause is extremely difficult with our current understanding of the nodule zinc proteome and the techniques to analyse it. The phenotype observed in symbiotic mtzip6 RNAi plants is consistent with that observed in soybean inoculated with $S$. fredii znuA mutant (Jiao et al., 2016), lacking a bacterial high-affinity Zn transporter (Vahling-Armstrong, Zhou, Benyon, Morgan, \& Duan, 2012), which is mainly expressed in nodule interzone and ZIII (Roux et al., 2014). This would suggest that Zn requirement for SNF is probably of bacterial origin. Among all the possible causes, we think it is unlikely that a bacterial zinc-dependent transcription factor regulating nitrogenase expression is involved, because nitrogenase protein levels are not altered in control and RNAi plants. More work needs to be done, and new technologies have to be developed towards characterizing the nodule zinc-proteome to better ascertain the molecular basis of the phenotype observed.

MtZIP6 is also expressed in the root vasculature, in a position consistent with the xylem parenchyma. However, the results obtained indicate that a reduction of $90 \%$ in MtZIP6 expression is not sufficient to confer any altered phenotype when plants are being watered with an ammonium nitrate-supplemented nutrient solution. This could be the result of a stable mRNA that would allow for enough protein synthesis to fulfil its role or of some other transporter partially complementing MtZIP6 function in the root vasculature. In addition, the phenotype observed for mtzip6 RNAi plants under symbiotic conditions is not the consequence of the loss of function of MtZIP6 in the root vasculature. If this were the case, we would detect less zinc reaching the nodules. However, the opposite is observed, with zinc localization studies showing that this metal is being delivered to the nodule apical region, but it is being retained there due to the reduction of the zinc uptake function of a knocked-down MtZIP6. This distribution pattern also supports a model in which other metals, and not just iron, are released by the vasculature in the apoplast of Zone II and indicates that this region is critical for nodule metal nutrition. Data on the effect of changing zinc concentrations on MtZIP6 transcription indicate a different expression profile in roots (where MtZIP6 levels change as a result of zinc levels) than in nodules (where it does not). One possible explanation is that nodule zinc levels are buffered, and consequently, there is little change in the expression in nodules of this gene. Alternatively, it might be hypothesized that the zinc-responsive transcription factor governing MtZIP6 expression in nodules is not functional (or plays a very minor role) in nodules. In roots, lower zinc levels in the nutrient solution result in upregulation of MtZIP6, likely a response to increase zinc delivery to sink organs. Similar induction is also observed at the two highest zinc concentrations tested, which could contribute to alleviate zinc accumulation in roots by translocating it to aerial parts as observed in hyperaccumulator plants (Dräger et al., 2004; Zhao, Lombi, Breedon, \& McGrath, 2000). As expected by the high zinc requirements of SNF (Ibrikci \& Moraghan, 1993; O'Hara, 2001), nodulation increases the response to low zinc (illustrated by the higher

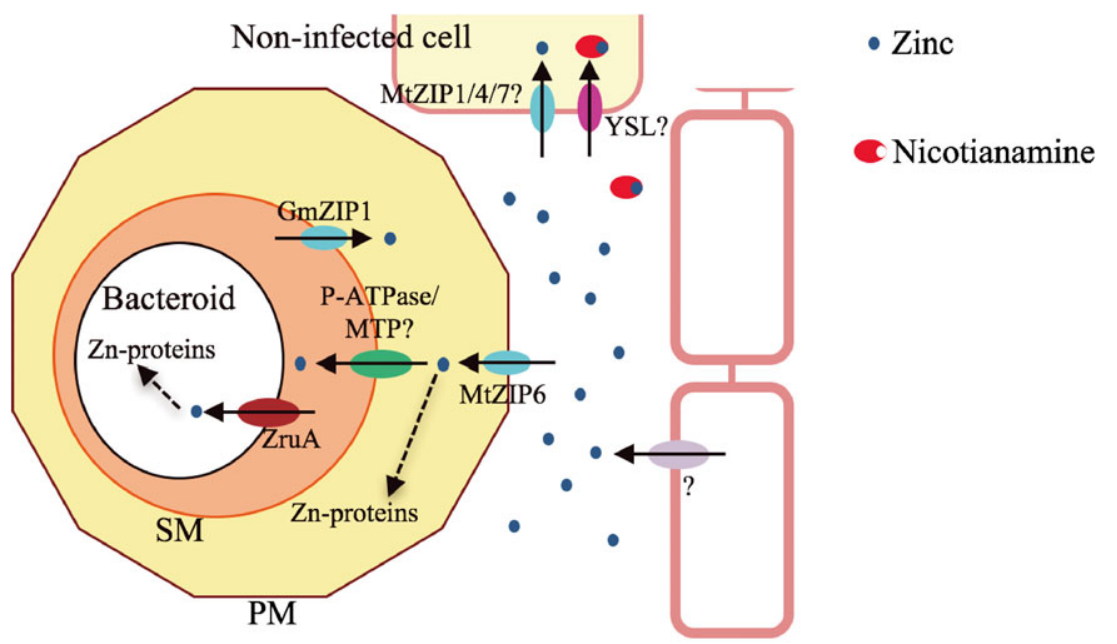

FIGURE 7 Zinc uptake by nodule cells. Zinc, as iron, is delivered by the vasculature and released in Zone II by yet-to-be-determined transporters. There, MtZIP6 would introduce zinc into rhizobia infected cells. Once in the cytosol a MTP, or a P-type ATPase, would be transporting zinc across the symbiosome membrane. To prevent symbiosome zinc overload, GmZIP1 would be pumping out excess zinc. ZnuA would be responsible for zinc uptake by the bacteroid. Once within the host cell or the bacteroid, this zinc will be used as cofactor for a number of zinc proteins, some of them with an important role in symbiotic nitrogen fixation. PM stands for plasma membrane, and SM for symbiosome Rhizobia-infected cell

Nodule endodermis 
expression of MtZIP6 in roots from inoculated vs. noninoculated plants), and it increases the substrate zinc concentrations required to elicit a detoxification response (explaining the lower expression of MtZIP6 in roots from inoculated vs. noninoculated plants).

It is also interesting to point out that MtZIP6 is only expressed in rhizobia-infected cells, a result supported by transcriptomic analyses of laser-captured microdissected cells (Limpens et al., 2013), raising the question of how zinc is taken up by non-infected cells. Being an essential micronutrient, these cells have to obtain zinc, and the likely candidates would be YSL or ZIP family members as indicated in Section 1. If it is a ZIP transporter, it will not be MtZIP6, and we would expect the other transporter to have a different affinity for zinc so that it could be differentially distributed between the two cell types. Putative candidates for zinc uptake by non-infected cells are MtZIP1, MtZIP4, or MtZIP7, ZIP transporters that are mainly expressed in non-infected nodule cells (Limpens et al., 2013). Alternatively, if zinc uptake by non-infected cells is mediated by a YSL transporter, a prerequisite for it is the requirement of nicotianamine for nodule functioning, something that has been recently shown (Avenhaus et al., 2016).

In conclusion, as summarized in the model presented in Figure 7 , zinc would reach the nodule by the vasculature and be released into the differentiation zone of the nodule, as is the case for iron (Rodríguez-Haas et al., 2013). There, MtZIP6 would introduce zinc into cells that are infected with rhizobia. Once in the cytosol, a fraction of the zinc could cross the symbiosome membrane to supply zinc for the bacteroid. This function has been proposed to be carried out by another ZIP transporter, GmZIP1 (Moreau et al., 2002). However, given the available information on the biochemistry and direction of transport of members of this family (Lin et al., 2010; Zhao \& Eide, 1996), it would more likely play a role in buffering zinc content in the symbiosome to prevent toxicity. Instead, a member of the CDF/MTP or $\mathrm{P}_{1 \mathrm{~B}}$-ATPase family could be potentially carrying out this role, because they can also transport zinc outside the cytosol, and they have been involved in metal upload to different organelles (DesbrossesFonrouge et al., 2005; Ellis et al., 2004; Eren \& Argüello, 2004; Hussain et al., 2004). Once within the nodule cell or the bacteroid cytosol, this zinc will be used to metallate proteins that have a key role in modulating nitrogenase activity in nodules. In addition, also working in Zone II, a ZIP or a YSL transporter would introduce zinc into non-infected cells.

\section{ACKNOWLEDGMENTS}

This research was funded by a grant from the Spanish Ministerio de Economía y Competitividad (AGL-2012-32974) and a European Research Council starting grant (ERC-2013-StG-335284), both to MG-G. RC-R was supported by a FPI fellowship from the Spanish Ministerio de Economía y Competitividad (BES-2013-062674).

We thank Rosabel Prieto (Universidad Politécnica de Madrid) for her excellent technical support. We would also like to thank Dr. Florian Frugier (Institute of Plant Sciences Paris-Saclay) for kindly sending us the pFRN vector and Dr. Luis M. Rubio (Universidad Politécnica de Madrid) for providing us with an anti-nifH antibody. We acknowledge the Paul Scherrer Institute, Villigen, Switzerland, for providing synchrotron radiation beamtime at the microXAS beamline of the Swiss Light Source (SLS).

\section{ORCID}

Isidro Abreu (D) http://orcid.org/0000-0002-1647-9883

\section{REFERENCES}

Alloway, B. J. (2008). Zinc in soils and crop nutrition (2nd ed.). International Zinc Association and International Fertilizer Industry Association.

Assunção, A. G. L., Herrero, E., Lin, Y. F., Huettel, B., Talukdar, S., ... Aarts, M. G. M. (2010). Arabidopsis thaliana transcription factors bZIP19 and bZIP23 regulate the adaptation to zinc deficiency. Proceedings of the National Academy of Sciences, USA, 107, 10296-10301.

Avenhaus, U., Cabeza, R. A., Liese, R., Lingner, A., Dittert, K., SalinasRiester, G., ... Schulze, J. (2016). Short-term molecular acclimation processes of legume nodules to increased external oxygen concentration. Frontiers in Plant Science, 6, 1012.

Bashir, K., Takahashi, R., Nakanishi, H., \& Nishizawa, N. K. (2013). The road to micronutrient biofortification of rice: Progress and prospects. Frontiers in Plant Science, 4, 15.

Boisson-Dernier, A., Chabaud, M., Garcia, F., Bécard, G., Rosenberg, C., \& Barker, D. G. (2001). Agrobacterium rhizogenes-transformed roots of Medicago truncatula for the study of nitrogen-fixing and endomycorrhizal symbiotic associations. Molecular Plant-Microbe Interactions, 14, 695-700.

Boye, J., Zare, F., \& Pletch, A. (2010). Pulse proteins: Processing, characterization, functional properties and applications in food and feed. Food Research International, 43, 414-431.

Brear, E. M., Day, D. A., \& Smith, P. M. C. (2013). Iron: An essential micronutrient for the legume-rhizobium symbiosis. Frontiers in Plant Science, 4, 359.

Brito, B., Palacios, J. M., Hidalgo, E., Imperial, J., \& Ruíz-Argüeso, T. (1994). Nickel availability to pea (Pisum sativum L.) plants limits hydrogenase activity of Rhizobium leguminosarum bv. viciae bacteroids by affecting the processing of the hydrogenase structural subunits. Journal of Bacteriology, 176, 5297-5303.

Broadley, M. R., White, P. J., Hammond, J. P., Zelko, I., \& Lux, A. (2007). Zinc in plants. New Phytologist, 173, 677-702.

Burton, J. W., Harlow, C., \& Theil, E. C. (1998). Evidence for reutilization of nodule iron in soybean seed development. Journal of Plant Nutrition, 5, 913-927.

Catalano, C. M., Czymmek, K. J., Gann, J. G., \& Sherrier, D. J. (2006). Medicago truncatula syntaxin SYP132 defines the symbiosome membrane and infection droplet membrane in root nodules. Planta, 225, 541-550.

Cheng, H. P., \& Walker, G. C. (1998). Succinoglycan is required for initiation and elongation of infection threads during nodulation of alfalfa by Rhizobium meliloti. Journal of Bacteriology, 180, 5183-5191.

Clarke, V. C., Loughlin, P. C., Day, D. A., \& Smith, P. M. C. (2014). Transport processes of the legume symbiosome membrane. Frontiers in Plant Science, $5,49$.

Curie, C., Cassin, G., Couch, D., Divol, F., Higuchi, K., Le Jean, M., ... Mari, S. (2008). Metal movement within the plant: Contribution of nicotianamine and yellow stripe 1-like transporters. Annals of Botany, 103, 1-11.

Desbrosses-Fonrouge, A. G., Voigt, K., Schroder, A., Arrivault, S., Thomine, S., \& Kramer, U. (2005). Arabidopsis thaliana MTP1 is a Zn transporter in the vacuolar membrane which mediates $\mathrm{Zn}$ detoxification and drives leaf $\mathrm{Zn}$ accumulation. FEBS Letters, 579, 4165-4174.

DiDonato, R. J., Roberts, L. A., Sanderson, T., Eisley, R. B., \& Walker, E. L. (2004). Arabidopsis Yellow Stripe-Like2 (YSL2) a metal-regulated gene encoding a plasma membrane transporter of nicotianamine-metal complexes. Plant Journal, 39, 403-414.

Downie, J. A. (2014). Legume nodulation. Current Biology., 24, R184-R190.

Dräger, D. B., Desbrosses-Fonrouge, A.-G., Krach, C., Chardonnens, A. N. Meyer, R. C., Saumitou-Laprade, P., \& Krämer, U. (2004). Two genes encoding Arabidopsis halleri MTP1 metal transport proteins 
co-segregate with zinc tolerance and account for high MTP1 transcript levels. Plant Journal, 39, 425-439.

Ellis, C. D., Wang, F., MacDiarmid, C. W., Clark, S., Lyons, T., \& Eide, D. J. (2004). Zinc and the Msc2 zinc transporter protein are required for endoplasmic reticulum function. Journal of Cell Biology, 166, 325-335.

Eren, E., \& Argüello, J. M. (2004). Arabidopsis HMA2, a divalent heavy metal-transporting $\mathrm{P}(\mathrm{IB})$-type ATPase, is involved in cytoplasmic $\mathrm{Zn}^{2+}$ homeostasis. Plant Physiology, 136, 3712-2723.

Finkelstein, J. (2009). Metalloproteins. Nature, 460, 813-813.

Frausto da Silva J.J.R. \& Williams R.J.P (2001) The biological chemistry of the elements.

González-Guerrero, M., Escudero, V., Sáez, A., \& Tejada-Jiménez, M. (2016). Transition metal transport in plants and associated endosymbionts: Arbuscular mycorrhizal fungi and rhizobia. Frontiers in Plant Science, 7, 1088.

González-Guerrero, M., Matthiadis, A., Sáez, Á., \& Long, T. A. (2014). Fixating on metals: New insights into the role of metals in nodulation and symbiotic nitrogen fixation. Frontiers in Plant Science, 5, 45.

González-Guerrero, M., Raimunda, D., Cheng, X., \& Argüello, J. M. (2010). Distinct functional roles of homologous $\mathrm{Cu}^{+}$efflux ATPases in Pseudomonas aeuginosa. Molecular Microbiology, 78, 1246-1258.

Guerinot, M. L. (2000). The ZIP family of metal transporters. Biochimica et Biophysica Acta, 1465, 190-198.

Hardy, R. W., Holsten, R. D., Jackson, E. K., \& Burns, R. C. (1968). The acetylene-ethylene assay for $\mathrm{n}(2)$ fixation: Laboratory and field evaluation. Plant Physiology, 43, 1185-1207.

Herridge, D. F., Peoples, M. B., \& Boddey, R. M. (2008). Global inputs of biological nitrogen fixation in agricultural systems. Plant and Soil, 311, $1-18$.

Hussain, D., Haydon, M. J., Wang, Y., Wong, E., Sherson, S. M., Young, J., ... Cobbett, C. S. (2004). P-type ATPase heavy metal transporters with roles in essential zinc homeostasis in Arabidopsis. Plant Cell, 16, 1327-1339.

Ibrikci, H., \& Moraghan, J. T. (1993). Differential responses of soybean and dry bean to zinc deficiency. Journal of Plant Nutrition, 16, 1791-1805.

Ishimaru, Y., Suzuki, M., Kobayashi, T., Takahashi, M., Nakanishi, H., Mori, S., \& Nishizawa, N. K. (2005). OsZIP4, a novel zinc-regulated zinc transporter in rice. Journal of Experimental Botany, 56, 3207-3214.

Jiao, J., Wu, L. J., Zhang, B., Hu, Y., Li, Y., Zhang, X. X., ... Tian, C. F. (2016). MucR is required for transcriptional activation of conserved ion transporters to support nitrogen fixation of Sinorhizobium fredii in soyben nodules. Molecular Plant-Microbe Interactions, 29, 352-361.

Kakar, K., Wandrey, M., Czechowski, T., Gaertner, T., Scheible, W.-R., Sitt, M., ... Udvardi, M. K. (2008). A community resource for high-throughput quantitative RT-PCR analyses of transcription factor gene expression in Medicago truncatula. Plant Methods, 4, 18.

Korshunova, Y. O., Eide, D., Clark, W. G., Guerinot, M. L., \& Pakrasi, H. B. (1999). The IRT1 protein from Arabidopsis thaliana is a metal transporter with a broad substrate range. Plant Molecular Biology, 40, 37-44.

Laity, J. H., Lee, B. M., \& Wright, P. E. (2001). Zinc finger proteins: New insights into structural and functional diversity. Current Opinion in Structural Biology, 11, 39-46.

Limpens, E., Moling, S., Hooiveld, G., Pereira, P. A., Bisseling, T., Becker, J. D., \& Küster, H. (2013). Cell- and tissue-specific transcriptome analyses of Medicago truncatula root nodules. PloS One, 8, e64377.

Lin, W., Chai, J., Love, J., \& Fu, D. (2010). Selective Electrodiffusion of zinc ions in a Zrt-, Irt-like protein, ZIPB. Journal of Biological Chemistry, 285, 39013-39020.

López-Millán, A. F., Ellis, D. R., \& Grusak, M. A. (2004). Identification and characterization of several new members of the ZIP family of metal ion transporters in Medicago truncatula. Plant Molecular Biology, 54, 583-596.

Moreau, S., Thomson, R. M., Kaiser, B. N., Trevaskis, B., Guerinot, M. L., Udvardi, M. K., ... Day, B. A. (2002). GmZIP1 encodes a symbiosis-specific zinc transporter in soybean. Journal of Biological Chemistry, 277, 4738-4746.

Mus, F., Crook, M. B., Garcia, K., Garcia Costas, A., Geddes, B. A., Kouri, E. D., ... Peters, J. W. (2016). Symbiotic nitrogen fixation and challenges to extending it to non-legumes. Applied and Environmental Microbiology, $82,3698-3710$

Nakagawa, T., Kurose, T., Hino, T., Tanaka, K., Kawamukai, M., ... Kimura, T. (2007). Development of series of gateway binary vectors, pGWBs, for realizing efficient construction of fusion genes for plant transformation. Journal of Bioscience and Bioengineering, 104, 34-41.

Nelson, B. K., Cai, X., \& Nebenführ, A. (2007). A multicolored set of in vivo organelle markers for co-localization studies in Arabidopsis and other plants. Plant Journal, 51, 1126-1136.

O'Hara, G. W. (2001). Nutritional constraints on root nodule bacteria affecting symbiotic nitrogen fixation: A review. Australian Journal of Experimental Agriculture., 41, 417-433.

Oldroyd, G. E. D. (2013). Speak, friend, and enter: Signalling systems that promote beneficial symbiotic associations in plants. Nature Reviewes Microbiology, 11, 252-263.

Olsen, L. I., Hansen, T. H., Larue, C., Østerberg, J. T., Hoffmann, R. D., ... Palmgren, M. (2016). Mother-plant-mediated pumping of zinc into the developing seed. Nature Plants, 2, 16036.

Olsen, L. I., \& Palmgren, M. G. (2014). Many rivers to cross: The journey of zinc from soil to seed. Frontiers in Plant Science, 5, 30.

Punshon, T., Guerinot, M. L., \& Lanzirotti, A. (2009). Using synchrotron $X$-ray fluorescence microprobes in the study of metal homeostasis in plants. Annals in Botany, 103, 665-672.

Quandt, H. J., Pühler, A., \& Broer, I. (1993). Transgenic root nodules of Vicia hirsuta: A fast and efficient system for the study of gene expression in indeterminate-type nodules. Molecular Plant-Microbe Interactions, 6, 699-706.

Rodríguez-Haas, B., Finney, L., Vogt, S., González-Melendi, P., Imperial, J., \& González-Guerrero, M. (2013). Iron distribution through the developmental stages of Medicago truncatula nodules. Metallomics, 5, 1247-1253.

Roux, B., Rodde, N., Jardinaud, M. F., Timmers, T., Sauviac, L., ... Gamas, P. (2014). An integrated analysis of plant and bacterial gene expression in symbiotic root nodules using laser-capture microdissection coupled to RNA sequencing. Plant Journal, 77, 817-837.

Saier, M. H., Reddy, V. S., Tamang, D. G., \& Västermark, Å. (2014). The transporter classification database. Nucleic Acids Research, 42, D251-D258.

Senovilla, M., Castro-Rodriguez, R., Abreu, I., Escudero, V., Kryvoruchko, I. S., Udvardi, M., Imperial, J. \& González-Guerrero, M. (2017). Medicago truncatula copper transporter1 (MtCOPT1) delivers copper form symbiotic nitrogen fixation. BioRxiv, https://doi.org/10.1101/104554

Sinclair, S. A., \& Krämer, U. (2012). The zinc homeostasis network of land plants. Biochimica et Biophysica Acta, 1823, 1553-1567.

Sinclair, S. A., Sherson, S. M., Jarvis, R., Camakaris, J., \& Cobbett, C. S. (2007). The use of the zinc-fluorophore, Zinpyr-1, in the study of zinc homeostasis in Arabidopsis roots. New Phytologist, 174, 39-45.

Soupène, E., Foussard, M., Boistard, P., Truchet, G., \& Batut, J. (1995). Oxygen as a key developmental regulator of rhizobium meliloti N2-fixation gene expression within the alfalfa root nodule. Proceedings of the National Academy of Sciences, USA, 92, 3759-3763.

Takanashi, K., Yokosho, K., Saeki, K., Sugiyama, A., Sato, S., Tabata, S., ... Yazaki, K. (2013). LjMATE1: A citrate transporter responsible for iron supply to the nodule infection zone of Lotus japonicus. Plant, Cell and Physiology, 54, 585-594.

Tejada-Jiménez, M., Castro-Rodríguez, R., Kryvoruchko, I., Lucas, M. M., Udvardi, M., Imperial, J., \& González-Guerrero, M. (2015). Medicago truncatula natural resistance-associated macrophage protein1 is required for iron uptake by rhizobia-infected nodule cells. Plant Physiology, 168, 258-272. 
Tejada-Jiménez, M., Gil-Díez, P., León-Mediavilla, J., Wen, J., Mysore, K. S., Imperial, J., \& González-Guerrero, M. (2017). Medicago truncatula molybdate transporter type 1 (MtMOT1.3) is a plasma membrane molybdenum transporter required for nitrogenase activity in root nodules under molybdenum deficiency. New Phytologist, https://doi: 10.1111/nph.14739

Udvardi, M., \& Poole, P. S. (2013). Transport and metabolism in legumerhizobia symbioses. Annual Review of Plant Biology, 64, 781-805.

Vahling-Armstrong, C. M., Zhou, H., Benyon, L., Morgan, J. K., \& Duan, Y. (2012). Two plant bacteria, S. meliloti and Ca. Liberibacter asiaticus, share functional znuABC homologues that encode for a high affinity zinc uptake system. PloS One, 7, e37340.

van Rhijn, P., \& Vanderleyden, J. (1995). The Rhizobium-plant symbiosis. Microbiological Reviews, 59, 124-142.

Vasse, J., de Billy, F., Camut, S., \& Truchet, G. (1990). Correlation between ultrastructural differentiation of bacteroids and nitrogen fixation in alfalfa nodules. J. Bacteriology, 172, 4295-4306.

Vernoud, V., Journet, E. P., \& Barker, D. G. (1999). MtENOD20, a Nod factor-inducible molecular marker for root cortical cell activation. Molecular Plant-Microbe Interactions, 12, 604-614.

Wessells, K. R., \& Brown, K. H. (2012). Estimating the global prevalence of zinc deficiency: Results based on zinc availability in national food supplies and the prevalence of stunting. PloS One, 7, e50568.
Yamaguchi, N., Ishikawa, S., Abe, T., Baba, K., Arao, T., \& Terada, Y. (2012). Role of the node in controlling traffic of cadmium, zinc, and manganese in rice. Journal of Experimental Botany, 63, 2729-2737.

Zhao, F. J., Lombi, E., Breedon, T., \& McGrath, S. P. (2000). Zinc hyperaccumulation and cellular distribution in Arabidopsis halleri. Plant, Cell \& Environment, 23, 507-514.

Zhao, H., \& Eide, D. (1996). The yeast ZRT1 gene encodes the zinc transporter protein of a high-affinity uptake system induced by zinc limitation. Proceedings of the National Academy of Sciences, USA, 93, 2454-2458.

\section{SUPPORTING INFORMATION}

Additional Supporting Information may be found online in the supporting information tab for this article.

How to cite this article: Abreu I, Saéz Á, Castro-Rodríguez R, et al. Medicago truncatula Zinc-Iron Permease6 provides zinc to rhizobia-infected nodule cells. Plant Cell Environ. 2017;40:2706-2719. https://doi.org/10.1111/pce.13035 